\title{
Arte de Joseph Beuys: pedagogia e hipermídia
}

Magda Salete Vicini ${ }^{1}$

Doutoranda em Comunicação e Semiótica pela Pontifícia Universidade Católica de São Paulo. Mestra em Educação, Arte e História da Cultura pela Universidade Presbiteriana Mackenzie (SP). Bacharel em Desenho e Plástica pela Universidade de Passo Fundo (RS). Professora de Design, Licenciatura em Artes e Ciências Biológicas na Universidade Oeste de Santa Catarina - UNOESC, Campus de Xanxerê (SC). Autora do livro Arte de Joseph Beuys: pedagogia e hipermídia, da editora Mackenzie.

E-mail: magdavicini@hotmail.com

Resumo: Como resultado de pesquisa da autora para seu mestrado na Universidade Mackenzie, a proposta deste artigo está ligada à preocupação com a arte como meio de comunicação, compreensão e ação dentro da universidade, através do encontro com a obra do artista Joseph Beuys e a hipermídia. São analisadas as obras: Coyote, "I Like America and America Likes me" (1974); Directional Forces (1974-1977); os múltiplos Zwei Fräulein mit leuchtendem Brot (1966) e Evervess II 1 (1967), bem como cartões-postais e feita citação de outras obras.

Palavras-chave: arte, Joseph Beuys, pedagogia e hipermídia.
Abstract: This article is concerned with art as a means of communication, understanding and action within a university. It relates to the encounter between the work of the artist Joseph Beuys and hypermedia as the result of research done for a Master's Degree at Mackenzie University. It analyses his works: Coyote, "I Like America and America Likes me" (1974); Directional Forces (1974-1977); the multiples Zwei Fräulein mit leuchtendem Brot (1966) and Evervess II 1 (1967); postcards and quotation of the other works.

Keywords: art, Joseph Beuys, pedagogy, hypermedia.
Joseph Beuys nasceu em Krefeld, Alemanha, em 1921, em plena República Weimar (1919-1932)*. Sua vida acadêmica iniciou-se em 1947, quando, depois de atuar como piloto de avião durante a Segunda Guerra Mundial, foi estudar Escultura Monumental na Academia de Artes de Düsseldorf, concluindo o curso em 1950. De 1963 a 1971, trabalhou como professor de Escultura nesta mesma academia.

Na década de 1960, conheceu o grupo Fluxus e as experiências de John Cage; a partir daí, compreendeu como seria sua obra artística: performances e ações, para comunicação com o público. Assim, criou o personagem Joseph Beuys e a Escultura Social ${ }^{2}$, com a qual, através de um processo mental de energia, de ações psicológicas e de interação de ideias discutidas com o público, pretendia combater o que julgava ser alienação. As Esculturas Sociais são formas de pensamento que, transformadas em palavras, provocam
Recebido: 30.06 .2008

Aprovado: 21.07 .2008

1. Disponível em: $<$ http://lattes.cnpq. br/2157773459376408>.

* A República de Weimar foi a forma de governo estabelecida na Alemanha em 1919, logo após a Primeira Guerra Mundial, com a Constituição de Weimar, assinada na cidade de mesmo nome. Desde o começo, a República enfrentou uma série de problemas políticos sociais e econômicos, culminando em $1933 \mathrm{com}$ a nomeação de Adolf Hitler e a consequente ascensão do nazismo. (N.E.)

2. LAUF, Cornelia. Joseph Beuys: the pedagogue as persona (Joseph Beuys: o caráter pedagógico). Columbia: Columbia University, 2000. p. 61-72. 
evoluções. Cada um é artista e as esculturas nunca estão terminadas, porque o pensamento está sempre em processo de reações, fermentações, decomposições. Tudo está constantemente em estado de mudança ${ }^{3}$. A interatividade é fundamental nesse processo, pois o ato de pensar produz energia entre as pessoas, e estas não conseguem ficar indiferentes ao ambiente. Nos encontros de Escultura Social aconteciam discussões sobre socialismo, arte, estética, política, entre outras, em busca de uma pedagogia para transformar a sociedade. Geralmente Beuys utilizava quadros negros para escrever suas ideias, através de palavras e diagramas, como fez na obra Directional Forces, apresentada em Londres (1974), Nova York (1975), Veneza (1976) e Berlim (1977).

A partir de Tisdall ${ }^{4}$ e das fotos de Directional Forces exibidas em Londres, descrevo como se deram estas Esculturas Sociais: Beuys instalava, em uma sala, quadros-negros, cavaletes e giz. O público surgia e, então, ele passa-

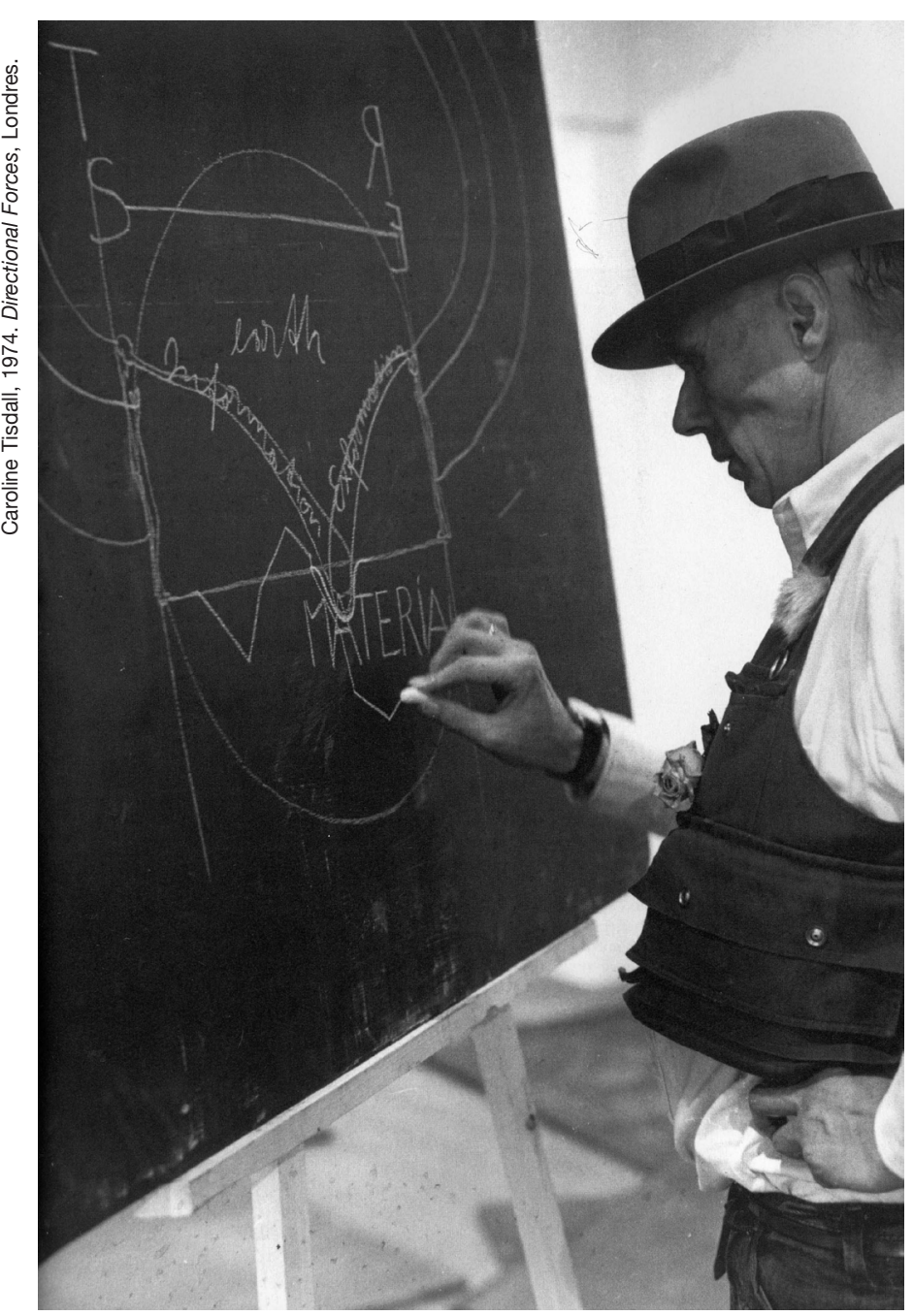

Com calça jeans, camisa branca, colete cheio de bolsos e chapéu de feltro, munido de um cajado ou bengala, como os pastores utilizam, Beuys assim se apresentava para as Esculturas Sociais, bem como no seu dia-a-dia (TISDALL, 1989). va a falar sobre suas ideias e escrevia-as nos quadros, interagindo, para a construção da escultura social. Depois de escritas, as ideias eram fixadas com spray e Beuys espalhava os quadros pelo chão do ambiente. As pessoas então andavam sobre as obras, escrevendo ou complementando com novas ideias. Este era o objetivo - discussão de ideias, uso da palavra, da interação, da mente, do conhecimento, da vivência e do corpo.

Em 1975, Beuys apresentou Directional Forces em Nova York, com outro enfoque, como uma obra completa, pois os quadros-negros haviam acabado. Mesmo assim, com alguns que restaram, o público 
pode escrever suas opiniões e interagir, dialogando com ele, participando da evolução psicológica de sua proposta ${ }^{5}$. A terceira exposição desta obra ocorreu no Pavilhão Internacional da Bienal de Veneza, em 1976: "Aqui, a intenção dele era colocar o ambiente todo atrás de um vidro, para ser contemplado como uma obra de arte acabada e inalcançável, exceto para o espectador tradicional, com ponto de vista atrás do vidro" ${ }^{6}$. A última aparição desta obra foi em 1977, em Berlim, também apresentada de forma diferenciada das demais: "Ela foi construída num canto e os quadros empilhados. Muito do sentido daqueles quadros, os dias e as experiências e acontecimentos que os preencheram, é vago. É a quarta e final transformação; portanto, como um 'afeto', ou uma bateria de informações"'.

Essa forma aleatória de apresentar seus trabalhos, a criatividade em adaptá-los de maneira a oferecer várias visões e concepções de diversos paradigmas e conceitos, com um mesmo material, faz da metodologia de Joseph Beuys uma máquina de expansão e inclusão de ideias, tendo a interdisciplinaridade como o caminho a seguir, a fenomenologia e a hermenêutica como alicerces para a produção de conhecimento. Características que acreditamos ser indispensáveis à metodologia de um ensino universitário que se propõe ser investigativo e integralizador.

Outro trabalho de Joseph Beuys, cuja metodologia nos faz refleti-la como obra pedagógica pelo conceito que esta envolve, chama-se Coyote, "I Like America and America Likes me", de 1974, realizada na Galeria de René Block, em Nova York. Nela, o artista ficou sete dias fechado em uma sala, convivendo com um coiote americano (pequeno lobo, símbolo mágico dos índios da América), pedaços de feltro, luvas, lanterna, um triângulo musical, uma bengala e o jornal The Wall Street (50 exemplares trocados diariamente). Na pilha de jornais, o coiote fazia suas necessidades fisiológicas ${ }^{8}$. Com o animal, ele se concentrou no que é o equivalente ao arquétipo americano, que o fez sentir afetado no curso da história dos Estados Unidos: "Eu

Joseph Beuys. Coyote, "I Like America and America Likes Me", 1974. Week-long action with coyote at Rene Block Gallery, New York Courtesy Ronald Feldman Arts, New York.

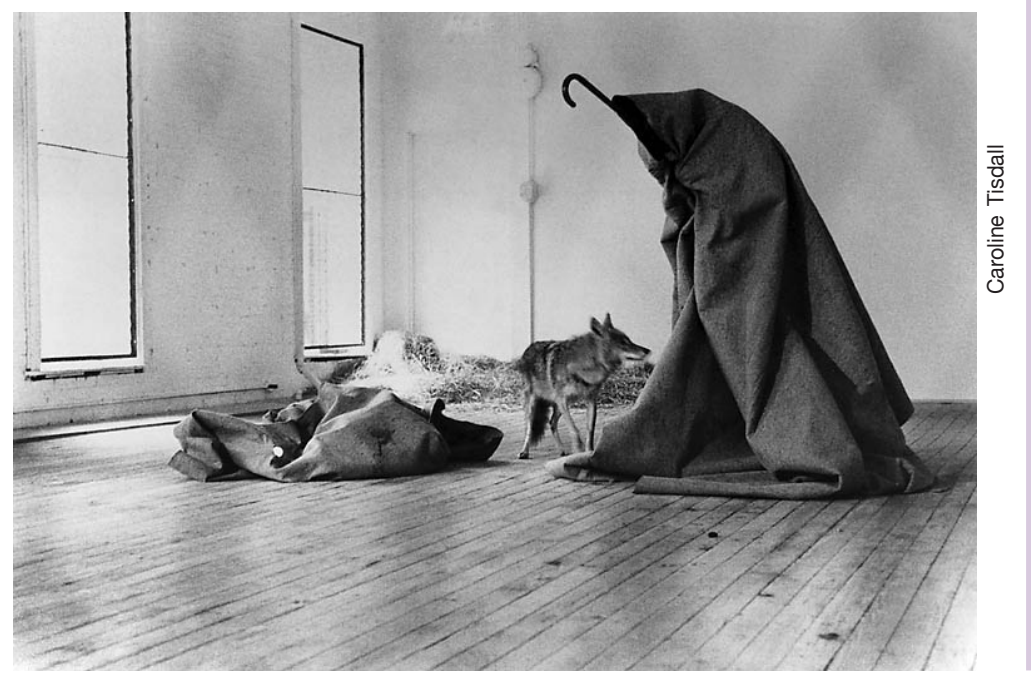

5. Ibid., p. 120.

6. Ibid., p. 132.

7. Ibid., p. 132.

8. Ibid., p. 159-162. 
9. BORER, Alan. Joseph Beuys. São Paulo: Cosac Naify, 2001. p. 170

10. KUONI, Carin. Joseph Beuys in America, cit., p. 44.

11. BEUYS, Joseph. Zeichnungen $=$ Tekeningen $=$ Drawings (Joseph Beuys: desenhos). Museum Boymans-Van Beuningen Rotterdam, November 1979-January 1980. Berlin: Nationalgalerie Berlin, Staatliche Museen Preussischer Kulturbesitz, c1979.

12. STAECK, Klaus. Beuys und das Jahr der Postkarten (Catálogo de cartões-postais de Beuys). Heidelberg: Editon Braus, 1998. p. 23.

13. GHIRARDELLI JR., Paulo. $O$ que é pedagogia? São Paulo: Brasiliense, 1987. p. 8-10.

14. DEWEY, John. Vida e educação. Tradução Anísio S. Teixeira. São Paulo: Edições Melhoramentos/ Fundação Nacional de Material Escolar, 1978. p. 14-16.

15. Transformação na teoria de Joseph Beuys; ele pretendia uma transformação através das Esculturas Sociais: uma passagem de um estado físico/mental para outro mais harmonioso, transparente (cf. KUONI, Carin. Joseph Beuys in América, cit., p. 9-19). acredito que consegui contactar com o ponto traumático da energia dos EUA: de todo americano com o índio, o homem vermelho"9.

Além das Esculturas Sociais, Joseph Beuys criava os múltiplos, ou seja, objetos fabricados, para também expressar suas teorias, ainda com objetivo de trocar ideias, provocar pensamentos e atitudes nas pessoas, pois ele estava empenhado na comunicação. Dizia que seus múltiplos eram trabalhos com imagens para transformar as ideias em algo físico, palpável, em jogos, para ir em direção a uma sociedade com mais liberdade e igualdade, que significava uma nova sociedade ${ }^{10}$; que seu interesse estava na relação desses objetos com o jogo (Spiel), como uma recordação (Art Erinnenrungsstütze), como um veículo (vehikel), os quais uma pessoa podia ter dentro da própria casa e associá-los com as ideias que ele queria difundir ${ }^{11}$. Através dos objetos, ele instiga à dúvida, à pesquisa, à reflexão constante do contexto em que vivemos, provocando uma atitude, um pensamento, uma transformação. A produção dos cartões-postais, que também podem ser chamados de múltiplos, iniciou-se em 1968, na Documenta de Kassel (Alemanha). Tinha o propósito de comunicar, informar e trocar informações. Ele deixava claro que dependia da ajuda das outras pessoas como multiplicadores: "Eu, sozinho, não posso dar conta da multiplicação. Por isso você deve fazê-la. Todos devem. Todos!"12.

\section{OS ASPECTOS PEDAGÓGICOS NA ARTE DE BEUYS}

Acreditamos no conceito de pedagogia como condução de uma criança, como "a preocupação com os meios, com as formas e maneiras de levar o indivíduo ao conhecimento" "13; um modo de comunicação entre indivíduos e conhecimento. A partir deste conceito, elaboramos as relações que se estabelecem entre Beuys e a pedagogia.

\section{Interatividade}

A interação entre indivíduo e sociedade, na qual Beuys praticava suas Esculturas Sociais, tem fundamentação a partir de Dewey, pois o artista fazia de sua experiência histórica e de vida os alicerces que o impulsionavam para a arte e para Dewey: "Experiência é uma fase da natureza. [...] é uma forma de interação, pela qual os dois elementos que nela entram - situação e agente - são modificados"14. Essa definição nos aproxima da teoria sobre a Escultura Social, múltiplos e cartões-postais, em que o contato com essas experiências provocavam uma "transubstanciação" ${ }^{15}$, ebulição de ideias, através da interação entre público e proposta prático-teórica. O objetivo era a produção de uma transformação (passagem). A interação faz parte de um jogo necessário, tanto no ato pedagógico do professor como na navegação de uma hipermídia, num enfrentamento de ideias onde tudo pode acontecer, e isso inspira liberdade e risco: "Por outro lado, essa liberdade não 
é sem risco. Antes, o próprio jogo é um risco para o jogador. Só se pode jogar com sérias possibilidades. [...] $\mathrm{O}$ atrativo que o jogo exerce sobre o jogador reside exatamente neste risco". Finalmente, o autor define: "Todo este espetáculo no jogo oferece a alegria do conhecimento"16.

\section{Construção/reconstrução e a qualidade da tradição}

Beuys está constantemente simulando, reconstruindo ambientes para o ato pedagógico, pois ele dizia que, como artista, era um professor. Da mesma forma, os ambientes hipermidiáticos têm esta característica, promovendo um novo olhar a cada ambiente navegado. Encontramos em Dewey o conceito de que educação é vida; ela não pode acontecer sem levar em consideração as experiências da vida e todo processo de transformação, aprendendo diretamente da vida: "Graças a esse hábito, a educação, como reconstrução contínua da experiência, fica assegurada como atributo permanente da vida humana"17. Construção e reconstrução que trazem à tona o conceito de tradição, que em Gadamer compreendemos:

[...] a tradição é essencialmente conservação e, como tal, está atuante nas mudanças históricas. No entanto, a conservação é um ato da razão, ainda que caracterizado pelo fato de não atrair a atenção sobre si. Essa é a razão por que as inovações, planejamentos intentem mostrar-se como única ação e resultado da razão ${ }^{18}$.

\section{Compreensão a partir de arte e estética}

Para Beuys, não havia outra forma de fazer algo para o homem a não ser através da arte. "E para isso eu preciso de uma concepção educacional; eu preciso de uma concepção da teoria da percepção, e eu preciso negociar." ${ }^{19}$ Para ele, educação significava arte, que é igual à criatividade, que é igual à liberdade humana. Dewey acredita que a arte é método para fazer refletir, quando define que uma verdadeira experiência precisa ter caráter intelectual, emocional e estético, percebendo que "o artista

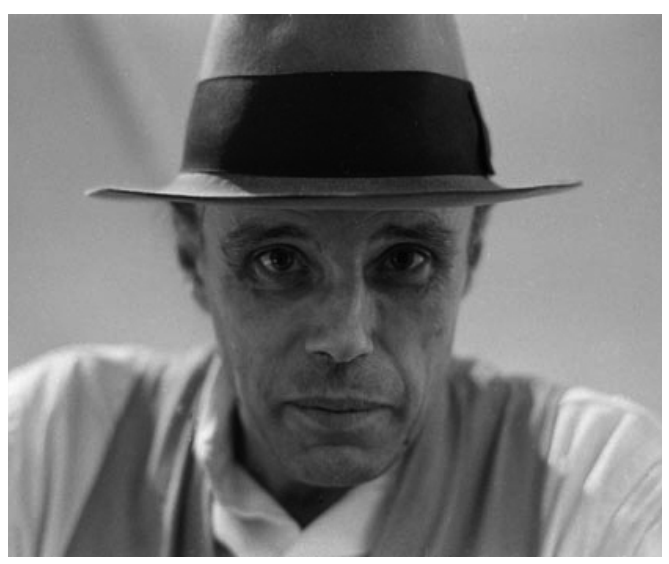

Retrato de Joseph Beuys, 1975. incorpora a si próprio a atitude do que percebe, enquanto trabalha" ${ }^{20}$. Assim, a compreensão a partir do fazer artístico instiga ao pensamento da origem das coisas e sua coisidade, em Heidegger ${ }^{21}$, que nada mais é que sua verdade de existir, mas nas mãos do artista e de quem se propõe à
16. GADAMER, Hans Georg. Verdade e método: traços fundamentais de uma hermenêutica filosófica. Petrópolis: Vozes, 1999. p. 180-189.

17. DEWEY, John. Vida e educação, cit., p. 17.

18. GADAMER, Hans Georg. Verdade e método, cit., p. 422.

19. ADRIANI, Götz; KONNERTZ, Winfrid; THOMAS, Karin. Joseph Beuys: life and works (Joseph Beuys: vida e trabaIhos). New York: Barron's Educational Series, Inc., 1979, p. 231.

20. DEWEY, John. Arte como experiência. Os pensadores. São Paulo: Abril, 1980. p. 99.

21. HEIDEGGER, Martin. A origem da obra de arte. Lisboa: Edições 70, 2000. 
compreensão; pode transformar-se em conhecimento ou estranhamento de uma nova concepção, porque não dizer, estética.

\section{A universidade}

Beuys sempre acreditou na Unidade na Diversidade, da mesma forma que Dewey acredita que a escola deva ser "um ambiente de integração social, onde ideias conflitantes possam co-habitar, seja no aspecto racial, religioso, seja qualquer outro que possa salientar as diferenças dos indivíduos" ${ }^{2}$. Sua vida como professor acadêmico foi sempre inquietante, sendo que, em 1972, foi expulso da Academia por liderar um grupo de estudantes que, mesmo não tendo passado no vestibular, queria fazer parte da Academia; ele acreditava que todos tinham direito ao conhecimento. Houve manifestação dos estudantes contra essa atitude da Academia, pois as aulas de Joseph Beuys possuíam audiência incomum. Esse fato o fez criar a Universidade Internacional Livre para a Pesquisa Interdisciplinar, FIU, em 1973, junto com o escritor Heinrich Böll. Segundo o manifesto de sua criação, a tarefa principal da escola é desenvolver o potencial criativo que temos dentro de nós, e que foi sucessivamente agredido e fez surgir o paradigma de que somente a arte tradicional poderia produzir artistas. Ao contrário, para eles:

A criação não envolve apenas talento, mas intuição, poder de imaginação e aplicação, bem como a habilidade de materializar o que poderia ser difundido para outras esferas relevantes. [...] a escola pode ser um seminário permanente no comportamento social e sua expressão articulada ${ }^{23}$.

Para enfatizarmos o conceito de escola propulsora do potencial criativo, encontramos suporte em Dewey, que acredita na atividade educativa como libertária: "De forças e tendências e impulsos existentes no indivíduo, e por ele mesmo trabalhados e exercitados, e, portanto, dirigidos, porque sem direção eles não se poderiam exercitar" ${ }^{24}$.

22. DEWEY, John. Vida e educação, cit., p. 25

23. KUONI, Carin. Joseph Beuys in America, cit., p. 149-150.

24. DEWEY, John. Vida e educação, cit., p. 25

25. FAZENDA, Ivani. Interdisciplinaridade: história, teoria e pesquisa. Campinas: Papirus, 2000. p. 29.

26. DEWEY, John. Vida e educação, cit., p. 48

\section{A interdisciplinaridade}

Partindo do conceito, interdisciplinaridade é "um tecido feito de fios bem trançados e maleáveis, onde a somatória de conhecimentos promove uma interação entre estes e o individuo" ${ }^{25}$. No aprendizado de Joseph Beuys existe um universo interdisciplinar através das Esculturas Sociais, ações, múltiplos, desenhos e pinturas; sua própria experiência de vida, ligada à definição de Dewey, que situa as matérias de estudo como:

[...] os resultados acumulados dos esforços das lutas e de êxitos da humanidade, apresentando-os não como simples acumulação confusa de pedaços isolados de experiências, mas como um corpo de verdades organizado e sistemático, isto é, racionalmente formulado ${ }^{26}$. 
Joseph Beuys utilizava todas as possibilidades de comunicação com o público através de sua arte, quer fisicamente, quer intelectualmente, tendo sempre uma atitude interdisciplinar, como vimos nos itens anteriores.

\section{HIPERMÍDIA: PEDAGOGIA PARA A EDUCAÇÃO INSPIRADA EM JOSEPH BEUYS}

A hipermídia, segundo Santaella, é:

A integração sem suturas de dados, textos, imagens de todas as espécies e sons dentro de um único ambiente de informação digital, na qual a interação é fundamental para que o navegador construa seu próprio mapa de navegação e conhecimento, pois em cada tela é preciso escolher um lugar para seguir, criando uma imersão de completa absorção, atenção e compreensão da informação ${ }^{27}$.

Consideramos que a metodologia de construção da hipermídia, bem como a navegação nesta, favorece o aprendizado, na medida em que instiga à construção de jogos de compreensão ${ }^{28}$, construção contínua ${ }^{29}$ e de significados diante daquilo que se apresenta, envolvendo o ser num ambiente esteticamente elaborado onde a arte tem seu habitar.

É essencial deixar claro que a hipermídia a que nos referimos trata-se de uma obra que tem como regra o conceito de autoria, como explica Bairon: "Nossa imersão, portanto, no mundo da hipermídia, tem sido, acima de tudo, um estilo metodológico de pensar a interdisciplinaridade a partir de um conceito de autoria"30. Da mesma forma, Joseph Beuys utiliza a arte

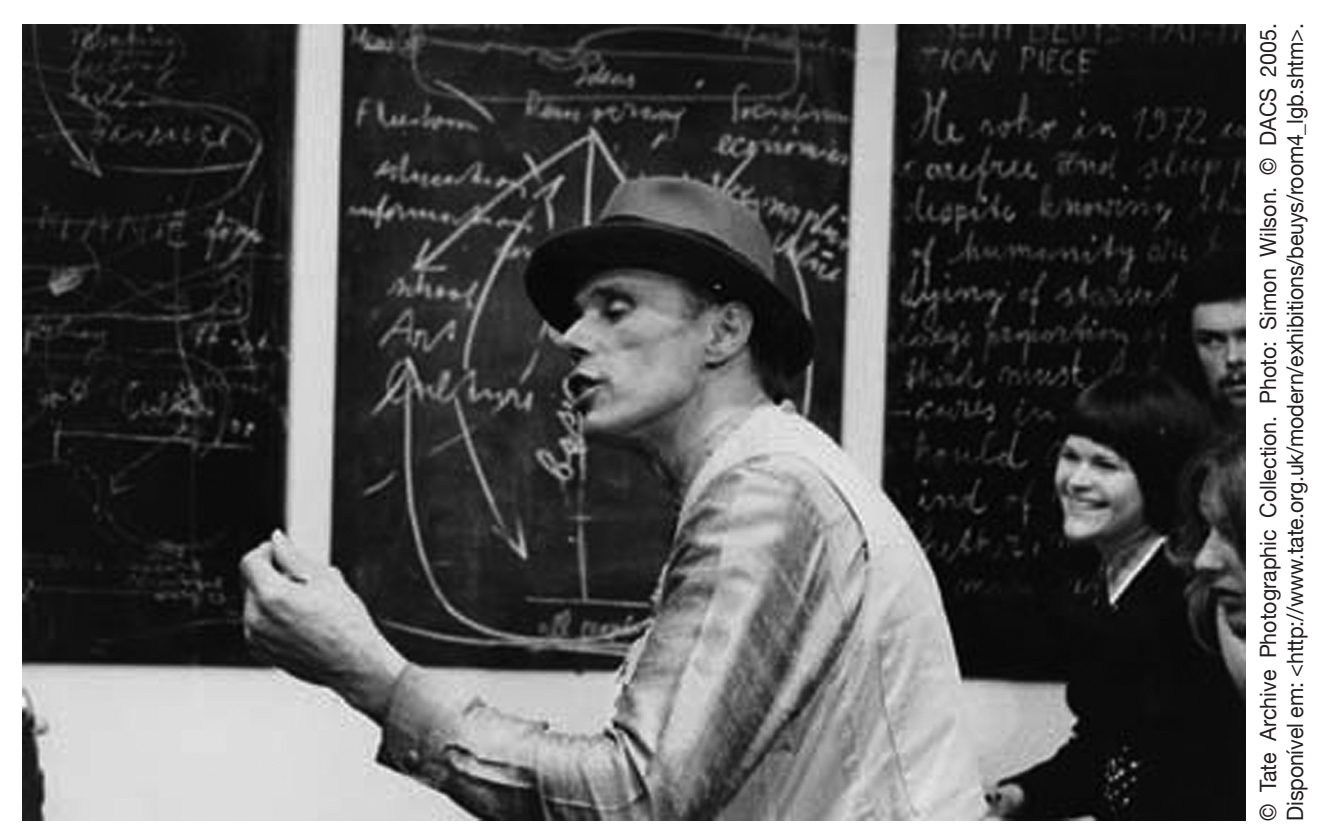

Joseph Beuys's Action Piece. 26-6 February, 1972.
27. SANTAELLA, Lucia. Matrizes da linguagem e do pensamento: sonora, visual e verbal. São Paulo: lluminuras, 2001. p. 394.

28. GADAMER, Hans Georg. Verdade e método, cit.

29. DEWEY, John. Vida e educação, cit.; Arte como experiência, cit.; $\mathrm{SCHÖN}$ Donald. Educando o profissional reflexivo: um novo design para o ensino e a aprendizagem. Porto Alegre: Artes Médicas, 2000.

30. BAIRON, Sergio. Interdisciplinaridade: educação, história da cultura e hipermídia. São Paulo: Futura, 2002. p. 123. 
31. BEUYS, Joseph. Zeichnungen $=$ Tekeningen $=$ Drawings (Joseph Beuys: desenhos). Museum Boymans-Van Beuningen Rotterdam, November 1979-January 1980. Berlin: Nationalgalerie Berlin, Staatliche Museen Preussischer Kulturbesitz, c1979. p. 96.

32. KUONI, Carin. Joseph Beuys in America, cit. p. 87.

33. Ibid., p. 71.

34. GADAMER, Hans Georg. Verdade e método, cit., p. $31-269$ comunicação \& educação • Ano XIV • Número 1 • jan/abr 2009

como metodologia: “[...] Questões como essas eram importantes para mim, quando tive que fazer minha decisão pela arte, usar a arte de um modo metodológico, para provocar as pessoas" ${ }^{31}$, pois para ele:

O homem é verdadeiramente vivo quando ele percebe que é criativo, um ser artístico. Eu peço que se tenha um envolvimento artístico em todo o domínio da vida. [...] Ao passo que eu defendo uma estética com envolvimento na ciência, economia, política e religião - todas as esferas da atividade humana ${ }^{32}$.

Um professor, em sua performance em sala de aula, constrói o saber ou o conhecimento, interagindo com os alunos e, assim, conceitos são estabelecidos a partir de autorias individuais, tanto do professor como dos alunos, interdisciplinarmente: escultura social. "Estou muito ciente antes de começar uma ação. Eu estou muito ciente sobre a ideia geral necessária na escultura, mas eu não sei nada sobre o processo no qual a ação vai transcorrer." ${ }^{33}$ Essa aleatoriedade é encontrada por todos os professores no cotidiano da sala de aula.

Em Gadamer encontramos um diálogo entre diversos conceitos que caracterizam e conduzem a uma teoria sobre a Liberação da Verdade desde a Experiência da Arte, em que a estética, a obra de arte, está intimamente relacionada ao ser histórico, sua formação, seu vivenciar como dasein, no sentido de deixar-se sofrer transformações e encontrar a configuração que não se limita ao ser novamente, mas, sim, ao ser o que é, levando consigo a representação de si mesmo em qualquer contexto ou espaço de tempo, ou seja, a verdade ${ }^{34}$. Propomos a experiência estética e da arte para a educação, a partir da metodologia de construção da hipermídia e das obras de Joseph Beuys.

\section{CONSIDERAÇÕES FINAIS}

A experiência da navegação na hipermídia conceitual e de autoria possibilita uma compreensão mais ampla não só através da navegação, mas também no momento da criação, como uma das metodologias que acreditamos estar mais próximas do nosso momento contemporâneo. O papel da arte, nesse contexto de aprendizagem, faz o sujeito interagir através da percepção que ela ativa em nosso processo cognitivo, pois trata de captar o mundo em suas particularidades e a nós mesmos com sua subjetividade, numa atitude e reflexão criativa que está presente em todos os seres humanos. Nesse sentido, a obra de Joseph Beuys pode contribuir para que a relação entre o saber e a arte se estabeleça, provocando uma transformação que acontece através da interação entre os assuntos pertinentes ao ser humano e seu contexto. 
A elaboração de sua metodologia de arte era resultado de profunda observação e reflexão, abordando o ser em sua interioridade e exterioridade, numa interdisciplinaridade que observamos ser a base fundamental na hipermídia, inclusive na sua constituição. Este processo leva a uma construção contínua, como em Dewey, em que o aprendizado é constante e cada sujeito estabelece seu aprendizado, sendo direcionado pelo professor que tem a função de um instrutor de caminhos. Joseph Beuys era a própria hipermídia: um ser que utilizava seu corpo, carregado de experiências e conhecimentos, emoções e atitudes, e apropriava-se disso tudo, deixandose tocar pelo mundo da experiência e do conhecimento, pelas emoções e atitudes fora dele, e transformar, através da arte, em códigos, símbolos, objetos, para que o outro interagisse com ele, experimentando ver o mundo com os olhos do próprio Joseph Beuys.

\section{REFERÊNCIAS BIBLIOGRÁFICAS}

ADRIANI, Götz; KONNERTZ, Winfrid; THOMAS, Karin. Joseph Beuys: life and works (Joseph Beuys: vida e trabalhos). New York: Barron's Educational Series, Inc., 1979.

BAIRON, Sergio. Interdisciplinaridade: educação, história da cultura e hipermídia. Futura: São Paulo, 2002.

BEUYS, Joseph. Zeichnungen $=$ Tekeningen $=$ Drawings $($ Joseph Beuys: desenhos). Museum Boymans-Van Beuningen Rotterdam, November 1979-January 1980. Berlin: Nationalgalerie Berlin, Staatliche Museen Preussischer Kulturbesitz, c1979.

BORER, Alan. Joseph Beuys. São Paulo: Cosac Naify, 2001.

DEWEY, John. Arte como experiência. Os pensadores. São Paulo: Abril, 1980.

. Vida e educação. Tradução Anísio S. Teixeira. São Paulo: Edições Melhoramentos/Fundação Nacional de Material Escolar, 1978.

FAZENDA, Ivani. Interdisciplinaridade: história, teoria e pesquisa. Campinas: Papirus, 2000.

GADAMER, Hans Georg. Verdade e método: traços fundamentais de uma hermenêutica filosófica. Petrópolis: Vozes, 1999.

GHIRARDELLI JR., Paulo. O que é pedagogia? São Paulo: Brasiliense, 1987.

HEIDEGGER, Martin. A origem da obra de arte. Lisboa: Edições 70, 2000.

KUONI, Carin. Joseph Beuys in América (Joseph Beuys na América). New York: Four Walls Eight Windows, 1993.

LAUF, Cornelia. Joseph Beuys: the pedagogue as persona (Joseph Beuys: o caráter pedagógico). Columbia: Columbia University, 2000. 
comunicação \& educação • Ano XIV • Número 1 • jan/abr 2009

SANTAELLA, Lucia. Matrizes da linguagem e do pensamento: sonora, visual e verbal. São Paulo, Iluminuras, 2001.

SCHÖN, Donald. Educando o profissional reflexivo: um novo design para o ensino e a aprendizagem. Porto Alegre: Artes Médicas, 2000.

STAECK, Klaus. Beuys und das Jahr der Postkarten (Catálogo de cartõespostais de Beuys). Heidelberg: Editon Braus, 1998.

TISDALL, Caroline. Joseph Beuys: we go this way (Joseph Beuys: vamos por este caminho). London: Violette Editons, 1989. 